\title{
Photoprotection as a Trait for Rice Yield Improvement: Status and Prospects
}

\author{
Erik H. Murchie ${ }^{1 *}$, Asgar Ali $^{2}$ and Tiara Herman ${ }^{2}$
}

\begin{abstract}
Solar radiation is essential for photosynthesis and global crop productivity but it is also variable in space and time, frequently being limiting or in excess of plant requirements depending on season, environment and microclimate. Photoprotective mechanisms at the chloroplast level help to avoid oxidative stress and photoinhibition, which is a light-induced reduction in photosynthetic quantum efficiency often caused by damage to photosystem II. There is convincing evidence that photoinhibition has a large impact on biomass production in crops and this may be especially high in rice, which is typically exposed to high tropical light levels. Thus far there has been little attention to photoinhibition as a target for improvement of crop yield. However, we now have sufficient evidence to examine avenues for alleviation of this particular stress and the physiological and genetic basis for improvement in rice and other crops. Here we examine this evidence and identify new areas for attention. In particular we discuss how photoprotective mechanisms must be optimised at both the molecular and the canopy level in order to coordinate with efficient photosynthetic regulation and realise an increased biomass and yield in rice.
\end{abstract}

Keywords: Rice; Photoprotection; Photosynthesis; Radiation; Chloroplast; Oxidative Stress; Photoinhibition

\section{Introduction}

As the only significant source of energy, incident solar radiation (sunlight) at the surface of the earth governs climate and the meteorological cycles and is essential for life. It has a major effect on the diurnal and seasonal temperature variations as well as the productivity of both terrestrial and aquatic plants by providing energy for the assimilation of carbon by plant canopies (Zhu et al. 2008b, Kambezidis et al. 2012). One of the most critical components affecting crop yield is the amount of solar radiation available to the plant, and the ability and efficiency with which biomass is produced (Russell et al. 1989; Murchie et al. 2009; Zhu et al. 2010). Indeed one of the cornerstones of crop productivity is the close relationship between intercepted radiation and biomass, which defines radiation use efficiency and maximum productivity (Monteith and Unsworth 1990; Murchie and Reynolds 2012). It is important for our understanding of crop productivity to incorporate spatial and temporal variation in light intensity. However, the reduction

\footnotetext{
* Correspondence: erik.murchie@nottingham.ac.uk

'Division of Plant and Crop Science, School of Biosciences, University of Nottingham, Sutton Bonington Campus, Leicestershire LE12 5RD, UK Full list of author information is available at the end of the article
}

of quantum yield that results from the inactivation of photosynthesis during high light episodes (termed photoinhibition) is rarely considered in this context, despite evidence that it can significantly affect yield and fitness in crops and model plant species (Zhu et al. 2004; Frenkel et al. 2007; Raven 2011). This may be particularly relevant for rice growing regions in South and Southeast Asia, which are positioned close to the equator where radiation can reach very high levels between periods of cloud cover. Here, the average annual solar irradiation can exceed $1800 \mathrm{kWh} / \mathrm{m}^{2}$, typical of the dry seasons in the tropics (data available at SolarGis.info). As an example, regions such as Central Luzon in the Philippines and Central and East Java in Indonesia can receive accumulative annual solar irradiation of more than $2200 \mathrm{kWh} \mathrm{m}^{-2}$. In regions that are environmentally vulnerable, higher light intensities could result in damage to crops and a significant reduction in yield. Photoinhibition is usually considered as a short-term response to periods of high light although is affected by long-term responses to environmental conditions (acclimation). In order to place photoinhibition in context with agricultural productivity which occurs over longer time scales it would be beneficial to link it with long term weather data. In this 
short review we summarise the current evidence that high irradiance levels result in significant yield reductions in rice crops at the metabolic and canopy levels.

\section{Review: Photosynthesis Under High Light: the Good and the Bad}

The physiological basis for high light 'stress' in plants originates within the process of energy absorption and transduction and the fact that there is a limited capacity for plants to utilise absorbed light energy. Photosynthesis is a complex physio-chemical process that converts light energy into chemical energy via the fixing of $\mathrm{CO}_{2}$ into sugars. Light is first absorbed by chlorophyll, located in the light-harvesting complexes of both photosystems I and II (PSI, PSII) within the thylakoid membrane. This creates resonance energy, which is then transferred through neighbouring chlorophyll molecules to photosystems. An excited chlorophyll $a$ molecule can return to ground state after light absorption through several pathways - photochemistry (photosynthesis), thermal dissipation, chlorophyll fluorescence or formation of a reactive oxygen species (ROS). The latter two are much less likely than the former (Murchie and Lawson 2013). Electrons are transferred from PSII to PSI via the redox reactions within the electron transport chain, coupled with the transfer of $\mathrm{H}^{+}$across the thylakoid membrane. The resulting NADPH and ATP are utilized in the Calvin-Benson cycle to reduce $\mathrm{CO}_{2}$ to organic compounds. However, the capacity of photosynthesis to utilise sunlight is limited, and more so in C3 plants such as rice. Moreover this is a highly erratic resource, fluctuating according to climate and season cycles and canopy position and it is clear that photosynthesis does not maintain a high efficiency during such transients leading to the risk of biomass loss and oxidative stress (Pearcy 1990; Murchie et al. 2009; Niinemets and Anten 2009).

\section{Photoinhibition: Classic and Contemporary Views}

Photoinhibition is a state describing the light-dependent decline in quantum yield and sometimes the photosynthetic capacity of photosynthetic organisms. It is common even in optimal conditions, especially under high light (Murchie et al. 1999) but is exacerbated by other physiological stresses such as drought (Raven 2011). It is usually considered to represent damage to the D1 protein within the PSII complex resulting in inactive reaction centres. A new D1 protein has to be synthesized and incorporated into the PSII core complex for PSII to regain functionality (Zhang et al. 2000; Aro et al. 2005). The balance between rate of damage and replacement of the D1 protein in the PSII reaction centre is important, with the rate of repair recently being highlighted (Murata et al. 2007). Repair of PSII is dependent on time, metabolic state and environmental conditions and is a limiting factor for the re-establishment of high quantum yield and photosynthesis (Aro et al. 2005; Takahashi and Badger 2011).

It may be difficult to separate the photosynthetic impact of photoinhibition with other metabolic perturbations caused by abiotic and biotic stresses. However it is clear that photoinhibition alone lowers $\Phi \mathrm{CO}_{2}$, (quantum yield of $\mathrm{CO}_{2}$ assimilation) resulting in a sustained decline in photosynthesis (Fig. 1). Light experienced by leaves within a canopy fluctuates over space and time: canopy photosynthesis is therefore the result of large populations of chloroplasts at different states of light saturation. Thus reduction in $\Phi \mathrm{CO}_{2}$ is visible during (temporary) low light episodes and can substantially limit photosynthesis (Ogren 1993; Zhu et al. 2004; Burgess et al. 2015). However, severe (chronic) photoinhibition can occur causing a decrease in both $\Phi \mathrm{CO}_{2}$ and $\mathrm{P}_{\max }$ (light-saturated photosynthesis) under very high light. While it has been suggested that under certain circumstances it may occur subsequent to photosynthetic down regulation or damage possibly associated with high carbohydrate levels (Adams et al. 2013), this is not consistent with observations of rice in the field (Murchie et al. 2002).

Photoinhibition has fascinated plant scientists for over half a century and there have been many studies that conclude that there is an impact on plant productivity (Raven 1989; Ogren 1993; Werner et al. 2001). Despite this a complete empirical and mechanistic understanding of its impact on crop yield is still lacking (Long et al. 1994; Murchie et al. 2009). One of the reasons for this may be the established principle that crop biomass positively correlates with intercepted light leading to the perception that low light is a bigger influence on yield. However this view is limited because it ignores the slope of this relationship, the canopy radiation use efficiency. This is itself limited by a number of factors including photoinhibition (see below and discussed in depth in Murchie et al. 2009). Modelling the effects of a delayed recovery of $\Phi \mathrm{CO}_{2}$ has consistently predicted a decline in canopy productivity as high as 30 \% (Ogren 1993; Zhu et al. 2004). This lack of clarity could be due to the difficulty in routine measurement of photoinhibition and canopy photosynthesis over long periods and the great dependency on environmental and metabolic states, which can affect both the initiation of photoinhibition and the rate of recovery. Advances in technology and modelling, like remote fluorescence monitoring may overcome these limitations by the continuous automated logging of fluorescence at many points in the plant canopy (Porcar-Castell 2011; Ruban and Murchie 2012).

\section{Photoprotection}

In order to reduce photoinhibition, plants have evolved a cascade of adaptive mechanisms at both leaf and cellular levels (Fig. 2) (Demmig-Adams and Adams 2006; 


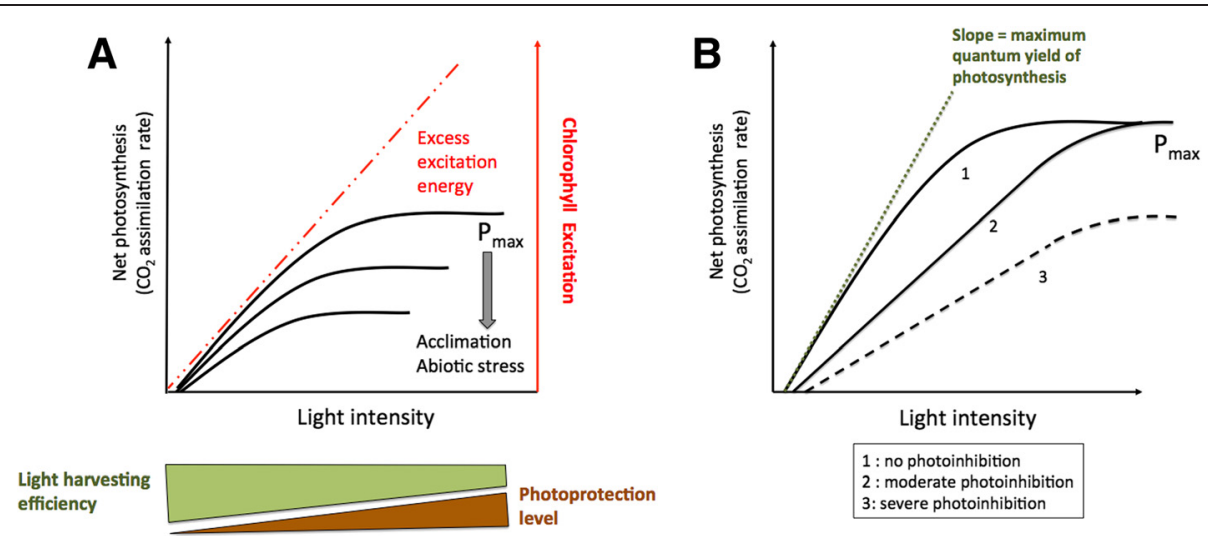

Fig. 1 The impact of photoinhibition on leaf photosynthetic efficiency. a: schematic depiction of how excess excitation energy is formed by the saturation of $\mathrm{CO}_{2}$ assimilation and the continued absorption of irradiance. This results in a lowering of light harvesting efficiency under low light as photoprotective processes such as NPQ begin to form and reach a maximum under high light. The proportion of excess excitation energy rises as $\mathrm{CO}_{2}$ assimilation capacity falls. $\mathbf{b}$ : schematic depiction of the lowering of quantum yield and maximum photosynthetic capacity according to the severity of photoinhibition (adapted from Murchie and Niyogi 2011)

Murchie and Niyogi 2011). Photoprotection can occur via the avoidance of high light or the metabolic processing of absorbed light energy to avoid oxidative stress. Avoidance can involve the repositioning of leaves to minimise light absorption and altering the angle of incidence to enhance reflection (Murchie et al. 2009) or the movement of chloroplasts along cell walls (Wada et al. 2003). In this way, leaf angle may be a major factor in the onset of photoinhibition (Murchie et al. 1999). Accumulation of UV- absorbing compounds, for example in the leaf cuticle, may also contribute to photoprotection (Hakala-Yatkin et al. 2010; Takahashi et al. 2010).

There are many photoprotective mechanisms located within the thylakoid membrane and these can be broadly divided into photochemical (involve electron sinks) or non-photochemical (occur prior to photolysis in PSII).

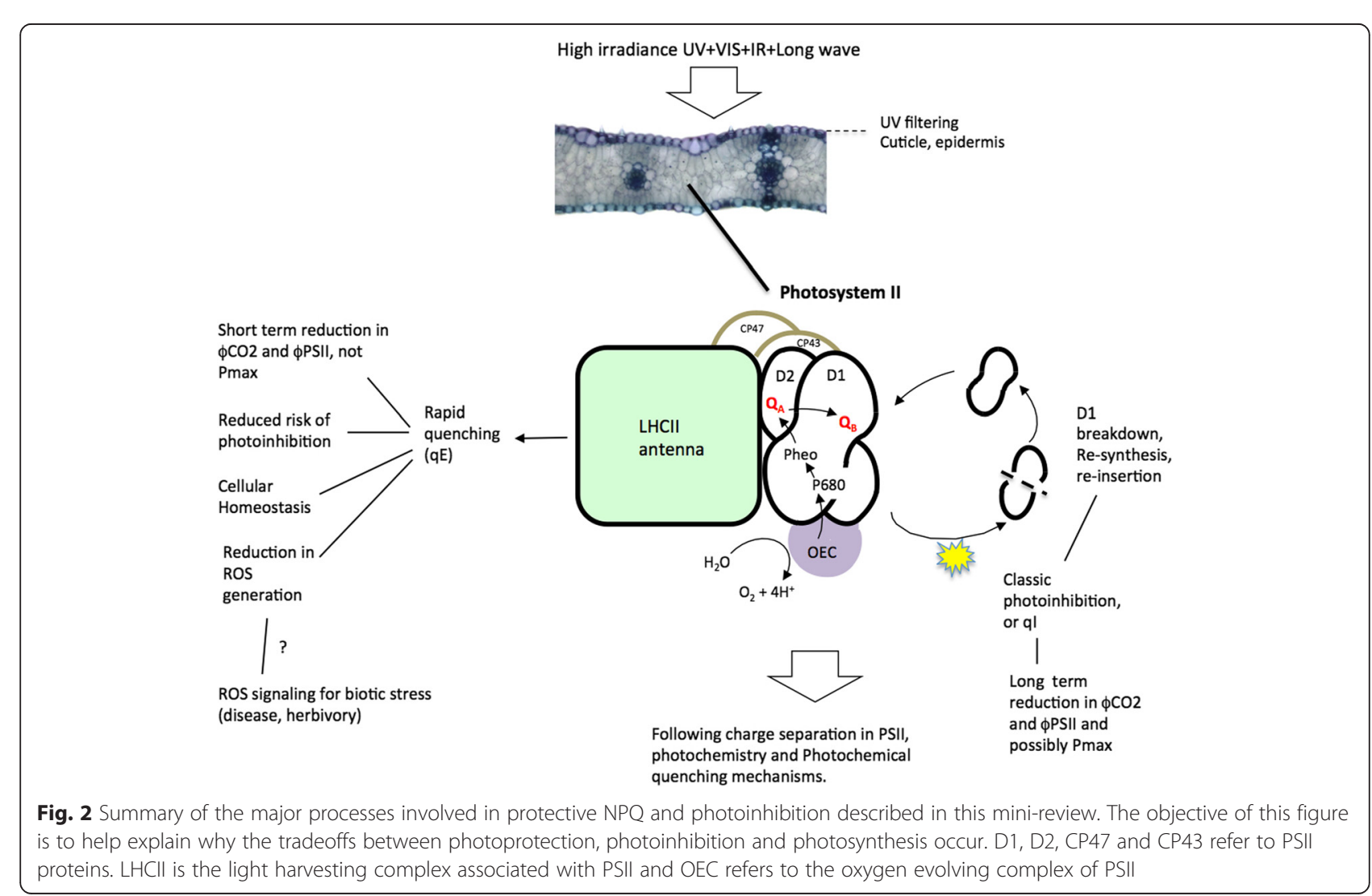


Non-photochemical quenching (NPQ) refers to the measurement of thermal dissipation of excess excitation energy in PSII (Horton and Ruban 2005; Belgio et al. 2014). The dominant form of NPQ is $\mathrm{qE}$, a rapidly reversible type of NPQ induced by the $\mathrm{pH}$ gradient $(\Delta \mathrm{pH})$ across the thylakoid membrane in high light. Acidification of the thylakoid lumen leads to a change in protonation of the PSII proteins resulting in an increased probability of energy dissipation (Ruban et al. 2012). Protonation activates the xanthophyll cycle (XC) which consists of the de-epoxidation of the xanthophyll carotenoid, violaxanthin, to the intermediate antheraxanthin and finally to zeaxanthin. The XC has a critical role in determining the kinetics of rise and decay of NPQ in plant tissue with the reconversion to zeaxanthin taking several minutes depending on environmental conditions (Demmig-Adams and Adams 2006; Johnson et al. 2008). Zeaxanthin has also been shown to be a highly effective antioxidant (see below). Another critical component of NPQ formation, capacity and kinetics is the PsbS protein, originally thought to be required for $\mathrm{qE}$ formation but now considered to be mainly involved in the enhancement of the capacity and rate of formation of $\mathrm{qE}$ by inducing structural changes in the thylakoid (Johnson and Ruban 2010). There is little doubt that $\mathrm{qE}$ acts in a protective manner. In Arabidopsis thaliana, the impairment of qE quenching via the mutation of genes encoding the PsbS (npq4) proteins has been shown to accelerate photoinhibition under strong light ( $\mathrm{Li}$ et al. 2002; Niyogi et al. 2005).

$\mathrm{qE}$ relaxes to zero within minutes of returning to darkness. A long-lived form of NPQ, labelled qI also exists and this can have multiple origins depending on the plant condition and environment (Horton et al. 2008). $\mathrm{qI}$ is also referred to as photoinhibition because it is measured the same way, i.e. as a sustained reduction in $\Phi P S I I$ and $\Phi \mathrm{CO}_{2}$ (Murchie and Lawson 2013). qI can also result from processes not associated with damage to PSII such as zeaxanthin retention (Demmig-Adams and Adams 2006). Since both qI and qE result in a decline in quantum yield they are sometimes referred to as chronic and dynamic photoinhibition respectively.

Any efficient sink for electrons may reduce the risk of photooxidative stress (see below) and photoinhibition. In fact, studies show a broad (negative) relationship that exists between the capacity to utilise light energy within photochemical sinks (carbon fixation and growth) and NPQ capacity (Demmig-Adams and Adams 2006). Fast growing species with a high capacity to generate biomass may have fewer requirements for protective quenching (see discussion below about photoinhibition and yield in rice). However the important point to make here is that besides photosynthesis itself, there are many mechanisms of photochemical quenching of excitation energy have been proposed including photorespiration, cyclic electron transport and the Mehler reaction (water-water cycle) (Murchie and Niyogi 2011).

Reactive oxygen species are readily generated in photosynthetic processes and this is central to the maintenance of photosynthetic efficiency and cellular signalling processes (Foyer and Noctor 2005; Murchie and Niyogi 2011). ROS are involved in the classical D1 turnover mechanism of photoinhibition described above and have been invoked in other mechanisms of PSII inactivation in different systems (Aro et al. 2005; Keren and KriegerLiszkay 2011). Recent work places a greater importance on the function of ROS on the rate of repair of PSII and also a more specific role of NPQ in this regard (Takahashi and Badger 2011). Regulation of ROS could prove important in the control of photoinhibition in the field. Important antioxidants include carotenoids, $\alpha$ tocopherol, glutathione and ascorbate. Johnson et al. (2007) showed that zeaxanthin, in addition to a key role in $\mathrm{qE}$ formation, was able to reduce lipid peroxidation in plants and improve whole plant tolerance to high light and temperature stress. A similar observation also made in rice ( $\mathrm{Du}$ et al. 2010). $\alpha$-tocopherol has recently been shown to be an important component of photoprotection in rice (Chen et al. 2014). Transgenic overexpressors of antioxidants such as glutathione reductase and superoxide dismutase (Foyer 1995), SOD (Kwon et al. 2002) and ascorbate peroxidase (Wang et al. 1999) have demonstrated the important role of radical scavenging. Generally there is a need to extend research into the role of such antioxidants in rice productivity ( $\mathrm{Du}$ et al. 2010; Chai et al. 2011; Zulfugarov et al. 2014).

\section{Photoinhibition in Rice}

Rice cultivars exhibit varying degrees of susceptibility to photoinhibition and thermal dissipation that are likely to be a result of evolution across different geological regions (Jiao et al. 2003; Kasajima et al. 2011). In many cases tropical japonica cultivars are found to be more prone to photoinhibition (Gesch and Heilman 1999; Murchie et al. 1999; Murchie et al. 2002; Jiao et al. 2003; Zhu et al. 2008b) and there is evidence that these differences are associated with the ability to regulate active oxygen and membrane stability (Jiao et al. 1992; Jiao and Ji 2001; Zhu et al. 2008a). However there may be a wider range of metabolic and physiological factors involved in the field that compound the effect of high light (Black et al. 1995; Chen et al. 2003; Wang et al. 2005) . Clearly there is scope for improvement if the correct genetic resources can be applied to breeding. One example of this is the genetic analysis of NPQ across a rice core collection (Kasajima et al. 2011). Here, higher NPQ was associated with Japonica cultivars in comparison to Indica. Remarkably the locus was associated with a PsbS 
homologue suggesting this gene may be a candidate for the higher photoprotective capacity in this ecotype, consistent with other overexpression analyses in rice (Hubbart et al. 2012). It is unclear why this contrasts with a previous quantitative trait loci study in A. thaliana that failed to associate NPQ with presence or PsbS (Jung and Niyogi 2009). It now seems likely that that PsbS and NPQ capacity may have a more important role in species such as rice that are adapted to higher light intensities (Hubbart et al. 2012).

Photoinhibitory losses occur at high radiation when yield potential is also highest. However this yield potential is still below theoretical maximum, one of the mechanisms being photoinhibition (Zhu et al. 2008b; Zhu et al. 2010). Depression in the photosynthetic capacity in rice can be observed in the field when irradiance exceeds saturation levels (around $1000 \mu \mathrm{mol} \mathrm{m} \mathrm{m}^{-2} \mathrm{~s}^{-1}$ ) (Black et al. 1995; Murchie et al. 1999; Wang et al. 2005). Indeed it is important to realise that such chronic photoinhibition in tropical rice exists even under optimal conditions in the field, as displayed by a significant decline in the quantum yield of carbon fixation at midday. In this scenario, the plants may initially experience high levels of $\mathrm{qE}$ only to shift to a more chronic form (qI) under increasing and sustained exposure to higher solar irradiances and/or other abiotic stresses. This midday depression results in an estimated loss of $30 \%$ of photosynthesis during the reproductive stage (Murchie et al. 1999; Horton 2000). This is often but not always associated with other metabolic factors including decreased stomatal conductance, an accumulation of carbohydrates and a decrease in ФPSII. Despite being a rainfed and irrigated crop, rice can be significantly affected by other environmental disturbances including periodic drought and submergence in lowland plantations in South and Southeast Asia (Wade et al. 1999; Zhou et al. 2007), caused by climate-related events such as El Niños. Heat stress is also common under natural field conditions, where temperatures and light intensities can reach $40{ }^{\circ} \mathrm{C}$ and beyond $1500 \mu \mathrm{mol} \mathrm{m} \mathrm{m}^{-2} \mathrm{~s}^{-1}$ respectively (Jagadish et al. 2010). Nutrient deficiency can also have an effect on photosynthetic capacity and susceptibility to photosynthesis in rice (Chen et al. 2003; Herman et al. 2015). All of these factors will compound the impact of photoinhibition.

\section{The way Forward: Improving Canopy Photoprotection to Improve Yield}

Exploitation of rice genetic resources may be limited by technical problems with the routine high throughput measurement of physiological traits such as NPQ and photoinhibition. Although both are easily measured by hand there is a required period of dark adaptation which can make application to mutant populations (tens of thousands of plant lines) difficult. However, the continued development of high-resolution phenotyping platforms (with automated darkening and light treatment) is expected to overcome this and uncover the genetic basis of these traits used in breeding programmes (Furbank and Tester 2011; Murchie and Harbinson 2015).

Photoprotection at the canopy level has not been fully addressed and there are outstanding questions concerning optimisation of photoprotection for canopy photosynthesis in the field (Murchie et al. 2009; Zhu et al. 2010). Intuitively, protection has beneficial effects to growth and yield because it reduces the likelihood of photoinhibition and photooxidative stress. Such effects have been shown for model species such as $A$. thaliana with varying levels of PsbS (Frenkel et al. 2009) but evidence for crops in the field is limited. Additionally the potential has been shown for over 'expression' of $\mathrm{qE}$ to result in down regulation of photosynthesis in fluctuating light which suggests that the reduction on quantum yield inherent within photoprotection creates a trade-off between control of oxidative stress and productivity (Figure 9 in Hubbart et al. 2012). To disentangle these effects to understand how photoprotection is involved in yield formation in rice we must consider photoprotective mechanisms solely in response to irradiance. We note there has been interesting recent work suggesting that NPQ is involved in the regulatory cross - talk in signalling responses to biotic factors. For example NPQ suppresses ROS formation and evidence shows that this can lead to plants being more palatable to herbivores (Jankanpaa et al. 2013). Recent work has suggested that activation of early defense reponses by pathogen -associated molecular patterns (PAMPS) triggers a temporary reduction in NPQ in order to permit and possibly as part of ROS mediated signalling and plant immunity (Göhre et al. 2012).

The lack of an empirical link between photoprotection and yield requires more explanation. First, it can be difficult to isolate photoprotective mechanisms as the origin of variations in productivity and yield. Photosynthesis has many mechanisms that can compensate for genetically induced variation in photochemical and nonphotochemical processes. Indeed NPQ can acclimate to the light environment and has a regulatory role in buffering the electron transport chain against rapid fluctuations in light (e.g. Murchie and Harbinson 2015). The use of knockout lines and overexpressors has demonstrated the role of some photoprotective processes in rice but impact at field and whole plant level has rarely been shown although we note studies that use additional abiotic stress such as drought (e.g. Du et al. 2010).

Conceptually there is a problem in quantifying thow protective' each process is (Ruban and Murchie 2012). Usually one would use control plants with no altered protection and compare to mutants or transgenics with 
a well-characterised genetic alteration. However it will be necessary to deconvolute the different mechanisms of photoprotection in the field to identify which compensatory processes are in action and this is technically difficult at the canopy scale. There are suggestions that photoinhibition in natural plant populations may occur as a result of down-regulation of photosynthesis which has itself been caused by carbohydrate accumulation (Adams et al. 2013), obscuring the effect of photoinhibition on photosynthesis. However no such effects have been observed in crops: in fact a large accumulation of leaf carbohydrate did not correlate with photoinhibition and photosynthesis (Murchie et al. 2002) so this mechanism does not appear to be present, in rice at least. Ultimately the role of photoprotection in crop yield will need to be demonstrated using canopy level practices such as those for measuring radiation use efficiency (Sinclair and Muchow 1999; Murchie and Reynolds 2012).

Second, crop canopy structure may have a substantial role. It defines the characteristics of light in space and time and can offer properties that both enhance and help to prevent photoinhibition. In most rice crop canopies the uppermost layers receive the highest radiation. Thus in dense canopies, upper layers may offer protection to those leaves lower down. Unfortunately, this is at the risk of productivity because upright leaves with efficient penetration are associated with the highest canopy photosynthesis rates (Sinclair and Muchow 1999; Murchie and Reynolds 2012). This is because erect leaved canopies also permit an accumulation of a high leaf area index and a more efficient distribution of photosynthesis by prevention of a high proportion of leaves forming a light-saturated state on the one hand or being overly light-limited on the other (Burgess et al. 2015). Such erect leaved canopies possess higher theoretical canopy photosynthetic rate and reduced risk of photoinhibition at midday (Murchie et al. 1999; Sinclair and Muchow 1999). This point is important because other yield components are close to optimisation (such as harvest index) and canopy photosynthesis is currently considered a significant trait in terms of enhancing rice yield (Murchie et al. 2009, Zhu et al. 2010).

Modelling of dynamic photoinhibition has shown that the complex 3D structure of crop canopies can result in significant reductions in carbon gain by virtue of the failure of photosynthesis to efficiently track the fluctuations in light that occur over a timescale of minutes and hours (Zhu et al. 2004; Song et al. 2013). This has also been shown using stomatal dynamics (Lawson and Blatt 2014). To emphasise, a denser canopy with a high extinction coefficient would reduce the occurrence of such fluctuations but at the risk of reducing potential productivity.
There are therefore likely to be a series of optimisations, unique for photoprotection, that operate according to canopy structure. It is possible to hypothesise that more photoprotection will be required in some circumstances (prolonged high light) and less under others (low light or during periods of moderate but rapid high - low transition). The patterns of photoprotection required will be determined by the proportion of canopy surface area exposed to high radiation that induces photoinhibition and the properties of light fluctuations that limit photosynthesis. So how can this problem be solved? Existing models of canopy photoinhibition can predict the impact of $\Phi \mathrm{CO}_{2}$ changes on canopy photosynthesis, using different approaches such as ray tracing within high resolution images of crop canopy structure to track light fluctuations in time according to canopy position (e.g. Ogren 1993; Werner et al. 2001; Zhu et al. 2004; Burgess et al. 2015). High throughput, high-resolution techniques for canopy imaging are under development and success has been achieved (Pound et al. 2014). These empirical approaches are essential for establishing the impact on yield but in order to predict and test the impact of individual components and to integrate these processes into wider photosynthetic metabolism it will be necessary to generate mechanistic models of both photoinhibition and photoprotection based on component kinetics. However we are a long way from models that are sufficiently parameterised to make this link despite recent progress at the thylakoid level (Zaks et al. 2012). The focus needs to be on linking dynamic canopy descriptions with metabolic models that integrate photoprotective processes with complete models of photosynthesis (Song et al. 2013; Zhu et al. 2013; Burgess et al. 2015). Predictions can then be tested using transgenic, mutant or introgression/wide crossing approaches.

\section{Conclusion: Towards an Uncertain Future}

The genetic improvement of crop yield will need to be integrative and consider multiple stress and signalling pathways in the plant. In this review we focus on responses to high light, which will compound the effects of other stresses. We have highlighted the weak links between leaf level effects and field yield and explain the case for a better understanding of canopy level optimisation.

Finally we note some novel and highly relevant climatic factors related to irradiance. Studies carried out since the 1990s found a decline in solar radiation at the surface of the earth between the 1950s and the 1980s (Wild and Wild 2009), a phenomenon now commonly identified as 'global dimming'. Recent studies have noted a trend reversal post 1980, known as 'global brightening'. Changes in atmospheric aerosols caused by pollution have been recognized as one of the key contributors in these effects (Ramanathan and Carmichael 2008). We 
propose that changes in future global radiation need to be considered carefully because they may represent a further need for photoprotection in areas where radiation is highest.

\section{Abbreviations \\ ATP: Adenosine Triphosphate; $\mathrm{CO}_{2}$ : Carbon Dioxide; GR: Glutamate Reductase; $\mathrm{H}^{+}$: Hydrogen lons; $\mathrm{H}_{2} \mathrm{O}_{2}$ : Hydrogen Peroxide; \\ $\mathrm{NADP}^{+}$: Nicotinamide Adenine Dinucleotide Phosphate; NADPH: Reduced Nicotinamide Adenine Dinucleotide Phosphate; NPQ: Non-photochemical Quenching; Pmax: Light-saturated Rate of Photosynthesis; PSI: Photosystem I; PSII: Photosystem II; ROS: Reactive Oxygen Species; qE: Rapid and Reversible form of Non-photochemical Quenching; ql: Sustained, Long Term form of Non-photochemical Quenching; SOD: Superoxide Dismutase; UV: Ultraviolet Radiation; XC: Xanthophyll Cycle; $\Delta \mathrm{pH}$ : Change in pH Across the Thylakoid Lumen; $\Phi \mathrm{CO}_{2}$ : Quantum Yield of Carbon Dioxide Assimilation; ФPSII: Operational Efficiency of Photosystem $\mathrm{I}_{;} \cdot \mathrm{O}_{2}^{-}$: Superoxide Radical.}

\section{Competing interests}

The authors declare that they have no competing interests.

\section{Authors' contributions}

This review was conceived by EHM and the manuscript was drafted by TH, EHM and AA. AA acted as a co-correspondong author. All authors read and approved of the final manuscript.

\section{Authors' informations}

EHM is an Associate Professor of crop science at the University of Nottingham and has worked with responses of rice to the light environment since 2006 including fieldwork in the Philippines (International Rice Research Institute). He has published over 40 papers and 9 book chapters in this and related areas. Tiara Herman is a PhD student working on rice canopy photosynthesis and abiotic stress. Asgar Ali is a Professor of Postharvest Physiology and technology at the University of Nottingham Malaysia and the founding director of the Centre of Excellence for Postharvest Biotechnology.

\section{Acknowledgements}

We wish to acknowledge The Ministry of Education (MOE), Malaysia for Long-term Research Grant Scheme LRGS (Food Security) Enhancing sustainable rice production) and Universiti Putra Malaysia for funding this research project and technical support for AA. E. Murchie receive funding from the UK BBSRC (BB/JOO3999/1).

\section{Author details}

${ }^{1}$ Division of Plant and Crop Science, School of Biosciences, University of Nottingham, Sutton Bonington Campus, Leicestershire LE12 5RD, UK. ${ }^{2}$ School of Biosciences, University of Nottingham Malaysia Campus, Semenyih 43500, Selangor Darul Ehsan, Malaysia.

Received: 2 April 2015 Accepted: 19 September 2015

Published online: 30 September 2015

\section{References}

Adams WW III, Muller O, Cohu CM, Demmig-Adams B (2013) May Photoinhibition be a Consequence, Rather than a Cause, of Limited Plant Productivity? Photosynth Res 117:31-44. doi:10.1007/s11120-013-9849-7

Aro EM, Suorsa M, Rokka A, Allahverdiyeva Y, Paakkarinen V, Saleem A, Battchikova N, Rintamäki E (2005) Dynamics of Photosystem II: A Proteomic Approach to Thylakoid Protein Complexes. J Exp Bot 56:347-56. doi:10.1093/jxb/eri041

Belgio E, Kapitonova E, Chmeliov J, Duffy CDP, Ungerer P, Valkunas L, Ruban AV (2014) Economic Photoprotection in Photosystem II That Retains a Complete Light-Harvesting System With Slow Energy Traps. Nat Commun 5:8. doi:10.1038/ncomms5433

Black CC, Tu ZP, Counce PA, Yao PF, Angelov MN (1995) An Integration of Photosynthetic Traits and Mechanisms that can Increase Crop Photosynthesis and Grain Production. Photosynth Res 46:169-75. doi:10.1007/bf00020427

Burgess AJ, Retkute R, Pound MP, Preston SP, Pridmore TP, Foulkes J, Jensen O, Murchie EH (2015) High-Resolution 3D Structural Data Quantifies the Impact of Photoinhibition on Long Term Carbon Gain in Wheat Canopies in the Field. Plant Physiol. doi:10.1104/pp.15.00722

Chai C, Fang J, Liu Y, Tong H, Gong Y, Wang Y, Liu M, Wang Y, Qian Q, Cheng Z, Chu C (2011) ZEBRA2, Encoding a Carotenoid Isomerase, is Involved in Photoprotection in Rice. Plant Mol Biol 75:211-21. doi:10.1007/s11103-010-9719-Z

Chen YZ, Murchie EH, Hubbart S, Horton P, Peng SB (2003) Effects of Season-Dependent Irradiance Levels and Nitrogen-Deficiency on Photosynthesis and Photoinhibition in Field-Grown Rice (Oryza Sativa). Physiol Plant 117:343-351

Chen D, Chen H, Zhang L, Shi X, Chen X (2014) Tocopherol-Deficient Rice Plants Display Increased Sensitivity to Photooxidative Stress. Planta 239:1351-62. doi:10.1007/s00425-014-2064-8

Demmig-Adams B, Adams WW III (2006) Photoprotection in an Ecological Context: The Remarkable Complexity of Thermal Energy Dissipation. New Phytol 172:11-21. doi:10.1111/j.1469-8137.2006.01835.x

Du H, Wang N, Cui F, Li X, Xiao J, Xiong L (2010) Characterization of the Beta-Carotene Hydroxylase Gene DSM2 Conferring Drought and Oxidative Stress Resistance by Increasing Xanthophylls and Abscisic Acid Synthesis in Rice. Plant Physiol 154:1304-18. doi:10.1104/pp.110.163741

Foyer C (1995) Overexpression of Glutathione Reductase but not Glutathione Synthetase Leads to Increases in Antioxidant Capacity and Resistance to Photoinhibition in Poplar Trees. PLANT Physiol 109:1047-57. doi:10.1104/pp.109.3.1047

Foyer CH, Noctor G (2005) Redox Homeostasis and Antioxidant Signaling: A Metabolic Interface Between Stress Perception and Physiological Responses. Plant Cell Online 17:1866-1875. doi:10.1105/tpc.105.033589

Frenkel M, Bellafiore S, Rochaix JD, Jansson S (2007) Hierarchy Amongst Photosynthetic Acclimation Responses for Plant Fitness. Physiol Plant 129:455-459. doi:10.1111/j.1399-3054.2006.00831.x

Frenkel M, Kulheim C, Jankanpaa HJ, Skogstrom O, Dall'Osto L, Agren J, Bassi R, Moritz T, Moen J, Jansson S (2009) Improper Excess Light Energy Dissipation in Arabidopsis Results in a Metabolic Reprogramming. BMC Plant Biol. doi:10.1186/1471-2229-9-12

Furbank RT, Tester M (2011) Phenomics - Technologies to Relieve the Phenotyping Bottleneck. Trends Plant Sci.16:635-644. doi:10.1016/j.tplants.2011.09.005

Gesch RW, Heilman JL (1999) Responses of Photosynthesis and Phosphorylation of the Light-Harvesting Complex of Photosystem II to Chilling Temperature in Ecologically Divergent Cultivars of Rice. Environ Exp Bot 41:257-266. doi:10.1016/s0098-8472(99)00008-8

Göhre V, Jones AME, Sklenář J, Robatzek S, Weber APM (2012) Molecular Crosstalk Between PAMP-Triggered Immunity and Photosynthesis. Mol Plant-Microbe Interact 25:1083-1092. doi:10.1094/MPMI-11-11-0301

Hakala-Yatkin M, Mantysaari M, Mattila H, Tyystjarvi E (2010) Contributions of Visible and Ultraviolet Parts of Sunlight to Photoinhibition. Plant Cell Physiol 51:1745-1753. doi:10.1093/pcp/pcq133

Herman T, Murchie EH, Warsi AA (2015) Rice Production and Climate Change: A Case Study of Malaysian Rice. Pertanika J Trop Agric Sci 38:321-328

Horton P (2000) Prospects for Crop Improvement Through the Genetic Manipulation of Photosynthesis: Morphological and Biochemical Aspects of Light Capture. J Exp Bot 51:475-485

Horton P, Ruban A (2005) Molecular Design of the Photosystem II Light-Harvesting Antenna: Photosynthesis and Photoprotection. J Exp Bot 56:365-373. doi:10.1093/jxb/eri023

Horton P, Johnson MP, Perez-Bueno ML, Kiss AZ, Ruban AV (2008) Photosynthetic Acclimation: Does the Dynamic Structure and Macro-Organisation of Photosystem II in Higher Plant Grana Membranes Regulate Light Harvesting States? Febs J 275:1069-1079

Hubbart S, Ajigboye OO, Horton P, Murchie EH (2012) The Photoprotective Protein PsbS Exerts Control Over CO2 Assimilation Rate in Fluctuating Light in Rice. Plant J 71:402-412. doi:10.1111/j.1365-313X.2012.04995.X

Jagadish SVK, Muthurajan R, Oane R, Wheeler TR, Heuer S, Bennett J, Craufurd PQ (2010) Physiological and Proteomic Approaches to Address Heat Tolerance During Anthesis in Rice (Oryza Sativa L.). J Exp Bot 61:143-156. doi:10.1093/ jxb/erp289

Jankanpaa HJ, Frenkel M, Zulfugarov I, Reichelt M, Krieger-Liszkay A, Mishra Y, Gershenzon J, Moen J, Lee C-H, Jansson S (2013) Non-Photochemical Quenching Capacity in Arabidopsis Thaliana Affects Herbivore Behaviour. PLoS One 8:1-12

Jiao DM, Ji BH (2001) Photoinhibition in Indica and Japonica Subspecies of Rice (Oryza Sativa) and their Reciprocal F-1 Hybrids. Aust J Plant Physiol 28:299-306 
Jiao DM, Ji BH, Li CG, Tong HY (1992) Photoinhibition of Indica and Japonica Rice and Their Reciprocal-f1 Hybrids. Photosynth Res 34:232

Jiao D, Ji B, Li X (2003) Characteristics of Chlorophyll Fluorescence and Membrane-Lipid Peroxidation During Senescence of Flag Leaf in Different Cultivars of Rice. Photosynth 41:33-41. doi:10.1023/a:1025848110029

Johnson MP, Ruban AV (2010) Arabidopsis Plants Lacking PsbS Protein Possess Photoprotective Energy Dissipation. Plant J 61:283-289. doi:10.1111/j.1365-313X.2009.04051.x

Johnson MP, Havaux M, Triantaphylidès C, Ksas B, Pascal AA, Robert B, Davison PA, Ruban AV, Horton P (2007) Elevated Zeaxanthin Bound to Oligomeric LHCII Enhances the Resistance of Arabidopsis to Photooxidative Stress by a Lipid-Protective, Antioxidant Mechanism. J Biol Chem 282:22605-18. doi:10.1074/jbc.M702831200

Johnson MP, Davison PA, Ruban AV, Horton P (2008) The Xanthophyll Cycle Pool Size Controls the Kinetics of non-Photochemical Quenching in Arabidopsis Thaliana. Febs Lett 582:262-266. doi:10.1016/j.febslet.2007.12.016

Jung H-S, Niyogi KK (2009) Quantitative Genetic Analysis of Thermal Dissipation in Arabidopsis. Plant Physiol 150:977-86. doi:10.1104/pp.109.137828

Kambezidis HD, Kaskaoutis DG, Kharol SK, Moorth KK, Satheesh SK, Kalapureddy MCR, Wild M (2012) Multi-decadal variation of the net downward shortwave radiation over south Asia: The solar dimming effect Atmospheric Environment. 50:360-372. http://doi.org/10.1016/j.atmosenv.2011.11.008

Kasajima I, Ebana K, Yamamoto T et al (2011) Molecular Distinction in Genetic Regulation of Nonphotochemical Quenching in Rice. Proc Natl Acad Sci U S A 108:13835-13840. doi:10.1073/pnas.1104809108

Keren N, Krieger-Liszkay A (2011) Photoinhibition: Molecular Mechanisms and Physiological Significance. Physiol Plant 142:1-5. doi:10.1111/ j.1399-3054.2011.01467.X

Kwon SY, Jeong YJ, Lee HS, Kim JS, Cho KY, Allen RD, Kwak SS (2002) Enhanced Tolerances of Transgenic Tobacco Plants Expressing Both Superoxide Dismutase and Ascorbate Peroxidase in Chloroplasts Against Methyl Viologen-Mediated Oxidative Stress. Plant Cell Environ 25:873-882. doi:10.1046/j.1365-3040.2002.00870.x

Lawson T, Blatt MR (2014) Stomatal Size, Speed, and Responsiveness Impact on Photosynthesis and Water Use Efficiency. Plant Physiol 164:1556-1570. doi:10.1104/pp.114.237107

Li X-P, Muller-Moule P, Gilmore AM, Niyogi KK (2002) PsbS-Dependent Enhancement of Feedback de-Excitation Protects Photosystem II from Photoinhibition. Proc Natl Acad Sci U S A 99:15222-7. doi:10.1073/pnas.232447699

Long SP, Humphries S, Falkowski PG (1994) Photoinhibition of Photosynthesis in Nature. Annu Rev Plant Physiol Plant Mol Biol 45:633-662

Monteith JL, Unsworth MH (1990) Principles of Environmental Physics. Edward Arnold, London

Murata N, Takahashi S, Nishiyama Y, Allakhverdiev SI (2007) Photoinhibition of Photosystem II Under Environmental Stress. Biochim Biophys Acta-Bioenergetics 1767:414-421. doi:10.1016/j.bbabio.2006.11.019

Murchie EH, Harbinson J (2015) NPQ Across Scales: From Chloroplasts to Plants to Communities. In: Demmig-Adams B, Adams WWIII (eds) Non-Photochemical Quenching and Energy Dissipation in Plants, Algae and Cyanobacteria. Springer, Dordrecht, Netherlands

Murchie EH, Lawson T (2013) Chlorophyll Fluorescence Analysis: A Guide to Good Practice and Understanding some new Applications. J Exp Bot 64:3983-98. doi:10.1093/jxb/ert208

Murchie EH, Niyogi KK (2011) Manipulation of Photoprotection to Improve Plant Photosynthesis. Plant Physiol 155:86-92. doi:10.1104/pp.110.168831

Murchie EH, Reynolds MP (2012) Crop radiation capture and use efficiency. Encycl Sustain Sci Technol 2615-2638. Meyer RA (Ed). Springer (New York). doi:10.1007/978-1-4419-0851-3_171

Murchie EH, Chen YZ, Hubbart S, Peng SB, Horton P (1999) Interactions Between Senescence and Leaf Orientation Determine in Situ Patterns of Photosynthesis and Photoinhibition in Field-Grown Rice. Plant Physiol 119:553-63

Murchie EH, Hubbart S, Chen YZ, Peng SB, Horton P (2002) Acclimation of Rice Photosynthesis to Irradiance Under Field Conditions. Plant Physiol 130:1999-2010

Murchie EH, Pinto M, Horton P (2009) Agriculture and the new Challenges for Photosynthesis Research. New Phytol 181:532-552. doi:10.1111/ j.1469-8137.2008.02705.x

Niinemets Ü, Anten N (2009) Packing the Photosynthetic Machinery: From Leaf to Canopy. In: Laisk A, Nedbal L (eds) Govindjee (eds) Photosynthesis in Silico: Understanding Complexity from Molecules to Ecosystems. Netherlands, Dordrecht, pp 363-399
Niyogi KK, Li XP, Rosenberg V, Jung HS (2005) Is PsbS the Site of non-Photochemical Quenching in Photosynthesis? J Exp Bot 56:375-382. doi:10.1093/jxb/eri056

Ogren E (1993) The Significance of Photoinhibition for Phtoosynthetic Productiviy. In: Baker NR, Bowyer JR (eds) Photoinhibiton of Phtoosynthesis from Molecular Mechanisms to the Field. Bios, Oxford

Pearcy RW (1990) Sunflecks and Photosynthesis in Plant Canopies. Annu Rev Plant Physiol Plant Mol Biol 41:421-453. doi:10.1146/annurev.pp.41.060190.002225

Porcar-Castell A (2011) A High-Resolution Portrait of the Annual Dynamics of Photochemical and Non-Photochemical Quenching in Needles of Pinus Sylvestris. Physiol Plant 143:139-53. doi:10.1111/j.1399-3054.2011.01488.x

Pound MP, French AP, Murchie EH, Pridmore TP (2014) Automated Recovery of Three-Dimensional Models of Plant Shoots from Multiple Color Images. Plant Physiol 166:1688-98. doi:10.1104/pp.114.248971

Ramanathan V, Carmichael G (2008) Global and Regional Climate Changes due to Black Carbon. Nat Geosci 1:221-227. doi:10.1038/ngeo156

Raven JA (1989) Fight or Flight - the Economics of Repair and Avoidance of Photoinhibition of Photosynthesis. Funct Ecol 3:5-19. doi:10.2307/2389670

Raven JA (2011) The Cost of Photoinhibition. Physiol Plant 142:87-104. doi:10.1111/j.1399-3054.2011.01465.x

Ruban AV, Murchie EH (2012) Assessing the Photoprotective Effectiveness of nonPhotochemical Chlorophyll Fluorescence Quenching: A new Approach. Biochim Biophys Acta-Bioenergetics 1817:977-982. doi:10.1016/j. bbabio.2012.03.026

Ruban AV, Johnson MP, Duffy CDP (2012) The Photoprotective Molecular Switch in the Photosystem II Antenna. Biochim Biophys Acta-Bioenergetics 1817:167-181. doi:10.1016/j.bbabio.2011.04.007

Russell G, Jarvis PG, Monteith J (1989) Plant Canopies: Their Growth, Form and Function. In: Russell G, Marshall B, Jarvis P (eds) Plant Canopies: Their Growth, Form and Function. Cambridge University Press, Cambridge, pp 21-41

Sinclair TR, Muchow RC (1999) Radiation use Efficiency. Advances in Agronomy, Vol 65:215-265

Song Q, Zhang G, Zhu X-G (2013) Optimal Crop Canopy Architecture to Maximise Canopy Photosynthetic CO2 Uptake Under Elevated CO2 - a Theoretical Study Using a Mechanistic Model of Canopy Photosynthesis. Funct Plant Biol 40:109-124. doi:10.1071/fp12056

Takahashi S, Badger MR (2011) Photoprotection in Plants: A new Light on Photosystem II Damage. Trends Plant Sci 16:53-60. doi:10.1016/j.tplants.2010.10.001

Takahashi S, Milward SE, Yamori W, Evans JR, Hillier W, Badger MR (2010) The Solar Action Spectrum of Photosystem II Damage. Plant Physiol 153:988-993

Wada M, Wada M, Kagawa T, Kagawa T, Sato Y, Sato Y (2003) Chloroplast Movement. Annu Rev Plant Biol 54:455-68. doi:10.1146/annurev. arplant.54.031902.135023

Wade L, Fukai S, Samson B, Ali A, Mazid M (1999) Rainfed Lowland Rice: Physical Environment and Cultivar Requirements. F Crop Res 64:3-12. doi:10.1016/S0378-4290(99)00047-7

Wang J, Zhang H, Allen RD (1999) Overexpression of an Arabidopsis Peroxisomal Ascorbate Peroxidase Gene in Tobacco Increases Protection Against Oxidative Stress. Plant Cell Physiol 40:725-732. doi:10.1093/oxfordjournals.pcp.a029599

Wang QA, Lu CM, Zhang QD (2005) Midday Photoinhibition of two Newly Developed Super-Rice Hybrids. Photosynthetica 43:277-281. doi:10.1007/s11099-005-0045-7

Werner C, Ryel RJ, Correia O, Beyschlag W (2001) Effects of Photoinhibition on Whole-Plant Carbon Gain Assessed With a Photosynthesis Model. Plant Cell Environ 24:27-40. doi:10.1046/j.1365-3040.2001.00651.x

Wild M, Wild M (2009) Global Dimming and Brightening: A Review. J Geophys Res 114:D00D16. doi:10.1029/2008JD011470

Zaks J, Amarnath K, Kramer DM, Niyogi KK, Fleming GR (2012) A Kinetic Model of Rapidly Reversible Nonphotochemical Quenching. Proc Natl Acad Sci U S A. 109:15757-15762. doi:10.1073/pnas.1211017109

Zhang L, Paakkarinen V, van Wijk KJ, Aro EM (2000) Biogenesis of the ChloroplastEncoded D1 Protein: Regulation of Translation Elongation, Insertion, and Assembly into Photosystem II. Plant Cell 12:1769-1782. doi:10.1105/tpc.12.9.1769

Zhou Y, Lam HM, Zhang J (2007) Inhibition of Photosynthesis and Energy Dissipation Induced by Water and High Light Stresses in Rice. J Exp Bot 58:1207-1217. doi:10.1093/jxb/erl291

Zhu XG, Ort DR, Whitmarsh J, Long SP (2004) The Slow Reversibility of Photosystem II Thermal Energy Dissipation on Transfer from High to low Light may Cause Large Losses in Carbon Gain by Crop Canopies: A Theoretical Analysis. J Exp Bot 55:1167-1175. doi:10.1093/jxb/erh141

Zhu SQ, Zhao H, Liang JS, Ji BH, Jiao DM (2008a) Relationships Between Phosphatidylglycerol Molecular Species of Thylakoid Membrane Lipids and 
Sensitivities to Chilling-Induced Photoinhibition in Rice. J Integr Plant Biol 50:194-202. doi:10.1111/j.1744-7909.2007.00610.x

Zhu X-G, Long SP, Ort DR (2008b) What is the Maximum Efficiency With Which Photosynthesis can Convert Solar Energy into Biomass? Curr Opin Biotechnol 19:153-9

Zhu X-G, Long SP, Ort DR (2010) Improving Photosynthetic Efficiency for Greater Yield. Annu Rev Plant Biol Vol 61(61):235-61. doi:10.1146/annurev-arplant042809-112206

Zhu X-G, Wang Y, Ort DR, Long SP (2013) e-Photosynthesis: A Comprehensive Dynamic Mechanistic Model of C3 Photosynthesis: From Light Capture to Sucrose Synthesis. Plant Cell Environ 36:1711-27. doi:10.1111/pce.12025

Zulfugarov IS, Tovuu A, Eu Y-J, Dogsom B, Poudyal RS, Nath K, Hall M, Banerjee M, Yoon UC, Moon Y-H, An G, Jansson S, Lee C-H (2014) Production of Superoxide from Photosystem II in a Rice (Oryza Sativa L.) Mutant Lacking PsbS. BMC Plant Biol 14:242. doi:10.1186/s12870-014-0242-2

Submit your manuscript to a SpringerOpen ${ }^{\circ}$ journal and benefit from:

- Convenient online submission

- Rigorous peer review

- Immediate publication on acceptance

- Open access: articles freely available online

- High visibility within the field

- Retaining the copyright to your article

Submit your next manuscript at $\gg$ springeropen.com 